\title{
Relationship between serum ghrelin levels, weight loss and quality of life in patients with advanced non-small cell lung cancer
}

\author{
Gökçen Demiray ${ }^{1}$, Serkan Degirmencioglu' ${ }^{2 *}$, Erhan Ugurlu ${ }^{3}$, Aydin Demiray ${ }^{4}$,Arzu Yaren ${ }^{2}$, Hakan Akca $^{4}$ and \\ Gamze Gököz Dogu² \\ ${ }^{1}$ Denizli State Hospital Medical Oncology Department,Pamukkale University Hospital FahriGoksin Oncology Center,Turkey \\ ${ }^{2}$ Pamukkale University Hospital Medical Oncology Department,FahriGoksin Oncology Center,Turkey \\ ${ }^{3}$ Pamukkale University Hospital Thoracic Oncology Department, Turkey \\ ${ }^{4}$ Pamukkale University Hospital Medical Biology Department,Turkey
}

Submission: May 30, 2018; Published: July 10, 2018

*Corresponding author: Serkan Degirmencioglu,Pamukkale University Hospital Fahri Goksin Oncology Center 20100 Denizli, Turkey; Tel: +905358333655; Email:drserkandeg@hotmail.com

Abstract

Cancer cachexia is one of the most frequent effects of malignancy, is often associated with poor prognosis, and may account for up to $20 \%$ of cancer deaths. The aim of our study was to evaluate the relationship with serum levels of ghrelin, weight loss, and quality of life in advanced non-small cell lung cancer patients.

Methods: A total of 67 chemotherapy-naïve advanced stage non-small cell cancer patients enrolled to study. Demographical, anthropometrical, laboratory data and serum levels of ghrelin were measured. Progression-free survival and overall survival were estimated using the Kaplan-Meier method. Survival among various factors was calculated using the log-rank test. Patients quality of life is evaluated with several questionnaires.

Results: Ghrelin levels were 4.6 - fold $(p=0.009)$ higher among patients with weight loss at the time of diagnosis. Lower serum levels of ghrelin were associated with better progression-free survival $(\mathrm{p}=0.011)$.

Conclusion: Serum ghrelin levels play key role as proinflammatory cytokines in lung cancer and weight loss; however, their use as diagnostic or prognostic markers is not possible yet and further large-scale studies are required to confirm our findings.

Keywords: Non-small cell lung cancer; Ghrelin; Weight loss; Quality of life

\section{Introduction}

Cancer cachexia is a complicated catabolic process which affects approximately two thirds of cancer patients and is caused by a systemic cascade in which many cytokines and mediators play role [1]. These mediators are often released by tumor cells. Cachexia development in cancer patients decreases treatment response and worsens tolerance, and thus affecting survival and quality of life [2]. Cancer cachexia may account for up to $20 \%$ of cancer deaths [2]. In a study conducted on prognostic value of weight loss, it was determined that weight loss was present in $59 \%$ of cases with small cell lung cancer, $58 \%$ of cases with non-small cell lung cancer (NSCLC), and $76 \%$ of cases with mesothelioma before the initiation of treatment [3].

Ghrelin is also named as appetite hormone [4]. Seventy percent of ghrelin is produced by X/A cells which are present in oxyntic mucosaand have endocrine logical functions. Ghrelin is a strong orexigenic (increasing appetite) molecule [5]. Ghrelin increases protein synthesis and carbon hydrate utilization, but it decreases fat utilization, so that energy gain and storage are performed [5]. Plasma ghrelin level is indirectly proportional to body mass index (BMI). Ghrelin level is increased in negative energy equilibrium [5]. The role of ghrelin in cancer and cancer induced cachexia is unknown. It is believed that ghrelin levels in cancer patients may be increased due to a systemic inflammation, and as a compensatory mechanism to catabolic process.In the present study, we aimed to reveal serum ghrelin levels in patients with advanced NSCLC, and its role in weight loss, and to evaluate its effects on quality of life as well as whether this peptide is a prognostic biomarker for cachexia. 


\section{Materials and Methods}

\section{Subjects}

A total of 67 chemotherapy-naïve patients who were admitted to Medical Oncology Department for the first time and were pathologically diagnosed as NSCLC were evaluated. A written informed consent was obtained from each participant. The study protocol was approved by the Medical Ethics Committee of Pamukkale University Medical Faculty (No: 02 / Date: 24.02.2009). The study was conducted in accordance with the principles of the Declaration of Helsinki.The patients at advanced stage (Stage IIIB and Stage IV) whose performance status (PS) was 0, 1, 2 according to the World Health Organization (WHO) classification were included in the study. The patients whose PS was 3 and worse on admission, those with cranial metastasis or suspicion of cranial metastasis, patients aged 80 and above, those at early stage (I, IIand IIIA), those the patients who were unwilling to give a written informed consent and who refused to answer the questionnaire were excluded from the study.Age, sex, anthropometric measurements, type of tumor, treatment, and the pre-treatment performances of the patients were recorded. The presence of weight loss at the time of diagnosis was questioned. Weight loss at the time of diagnosis was defined as a loss of more than $10 \%$ within the past six months.

\section{Biochemical analysis}

Blood samples were taken before treatment in the patient group and blood samples were taken between 08:00 and 09:00 A.M. following an 8-12 hour fasting. A complete blood count was measured using the CELL-DYN 3700 Systems and CELL-DYN Sapphire device. Ferritin, C - reactive peptid (CRP), glucose, insulin, and cortisole, albumin was measured with Roche/Hitachi Cobas c Systems, e 601 Module device. For the analysis of insulin resistance, the Homeostasis Model Assessment (HOMA-IR, Homeostasis Model Assessment) tool which provides practical examination of beta-cell function and insulin resistance using fasting glucose and insulin levels was used. It was calculated as fasting insulin value $(\mu \mathrm{IU} / \mathrm{mL}) \mathrm{x}$ fasting glucose level (mg/dl)/405. In healthy individuals, HOMA value is lower than 2.7 , while values above 2.7 indicates insulin resistance [6].Furthermore, $6 \mathrm{ml}$ of venous blood samples were taken from patients, for ghrelin analysis and the samples were taken to vacuumed tubes and the samples were centrifuged at $15,000 \mathrm{rpm}$ for 10 minutes. Serum was, then, separated and stored in a deep freezer at $-70^{\circ} \mathrm{C}$. It was measured by Enzymelinked immunosorbent Assay (ELISA) method (Digital and Analog System, DAS, Plombara Sabina, Italy). The cut-off value of ghrelin was calculated using an automatic program. The cutoff value for ghrelin was $1275 \mathrm{pg} / \mathrm{ml}$. The values at and below this value were evaluated as low and the values above this value were evaluated as high.

\section{Questionnaires}

Patients' quality of life was assessed by conducting a questionnaire and nutritional status were assessed by subjective global evaluation concurrently with blood sample collection. European Organization for Research and Treatment of Cancer Quality of Life Questionnaire (EORTC-QLQ-C30) the validity and reliability of the Turkish version of European Organization for Research and Treatment of Cancer Quality of Life (EORTCQLQ-C30) (version 3) was performed previously [7]. This tool is widely used in cancer patients all over the world. The scale evaluates health status and quality of life. On the function scale, there are questions about physical function, role function, emotional function, comprehension function, and social function; and functions to sustain daily activities are inquired. On the symptom scale, fatigue, nausea and vomiting, pain, dyspnea, insomnia, loss of appetite, constipation, diarrhea, and financial status are inquired. The last two questions represent the general health status scaleand show patients' self-assessment on quality of life as a whole. Functional, symptom, and general health status scores of the patients in EORTC-QLQ-C30 were determined with a scoring guideline created by using formulas [8]. Higher functional and general health status scores and lower symptom scores indicates a better quality of life for the patients.

\section{Quality of life questionnaire, short form 36 (SF-36)}

Short form 36, has a generic measurement characteristic among quality of life questionnaires and provides a wide range of measurement; it has been developed by Rand Cooperation and the validity and reliability studies of the Turkish version has been performed previously [9]. It is a self-assessment scale. Lower score indicates poor health status, whereas higher score indicates good health status.

\section{Hospital anxiety and depression (HAD) scale}

Hospital anxiety and depression scale has been specifically developed to use in hospital settings. It is a self-assessment scale to determine the risk of anxiety and depression and measure the level and change in the severity of them in the patient. The scale has been applied to various diseases, and compared between clinical groups, and it is shown that it indicates clinically significant results as a screening tool [10]. HAD scale has been translated into Turkish and the validity and reliability studies of the Turkish version has been performed, and it has been reported as a suitable tool in Turkey [11].

\section{Statistical Analysis}

Statistical analysis was performed by SPSS-16.0 for windows package program. Results were evaluated at a confidence interval of $95 \%$. The level of statistically significance was accepted as $\mathrm{p}<0.05$. Spearman and Pearson correlation test was used in correlation analyses. Kaplan-Meier method was used for overall survival (OS) and progression-free survival (PFS) curves. Logistic regression was used for analysis of factors affecting survival and progression.

\section{Results}

A total of 67 patients diagnosed with advanced (stage IIIb and IV) NSCLC were included in the study. Of patients, 62 
(92.5\%) were males, and 5 (7.5\%) were females. Patients were divided into two groups according to weight loss at the time of diagnosis. The main clinical and demographic characteristics of patients with and without weight loss at the time of diagnosis are shown in (Table 1).Ghrelin levels were 4.6-fold ( $p=0.009$ ) higher among patients with weight loss at the time of diagnosis, calculated with Mann Whitney U test. No significant difference was found between ghrelin and sex, PS, smoking, anemia, CRP, ferritin, cortisole, albumin levels, and IR.

Table1: Characteristics of patients with and without weight loss at the time of diagnosis (mean $\pm S D$ ).

\begin{tabular}{|c|c|c|c|}
\hline & Patients without WeightLoss \\
$(\mathrm{n}=25)$ & Patients with Weight loss (n=42) & p value \\
\hline Sex (Female/Male) & $0 / 25$ & $64.2 \pm 1.4$ & 0.073 \\
\hline Age (year) & $60.8 \pm 1.4$ & $24.2 \pm 5.2$ & $9 / 26 / 7$ \\
\hline Body mass index (BMI) & $27.4 \pm 3.6$ & 35 & 0.12 \\
\hline Histological type (A/S/O) & $6 / 18 / 1$ & $4.0 \pm 0.0$ \\
\hline Smoker (present) & 19 & $1471.7 \pm 62.1$ & 0.299 \\
\hline Albumin (g/dl) & $4.2 \pm 0.0$ & $25 / 17$ & 0.539 \\
\hline Ghrelin (Pg./ml) & $1232.3 \pm 70.4$ & $15 / 10$ & $0.009 *$ \\
\hline
\end{tabular}

Mann Whitney test. * $p<0.05$ indicates statistical significance. A: Adenocarcinoma, S: Squamous-cell carcinoma, O: Other subtypes.

Patients with low ghrelin levels, physical $(\mathrm{p}=0.004)$ and role $(\mathrm{p}=0.015)$ function scores of EORTC-QLQ-C30 subscales and physical function $(\mathrm{p}=0.006)$, pain $(\mathrm{p}=0.004)$, and mental function $(p=0.003)$ scores of SF-36 subscales were measured higher; fatigue $(\mathrm{p}=0.002)$ and pain $(\mathrm{p}=0.023)$ scores of EORTC-QLQ-C30 subscales were found higher. Besides, in these patient's anxiety $(p=0.023)$ and depression $(p=0.016)$ scores in HAD scale, and nutritional status $(\mathrm{p}=0.026)$ scores were normal.

When subscales of EORTC-QLQ-C30 and SF-36 questionnaires were examined, physical ( $p=0.008$, and $p=0.032$, respectively) and role function $(\mathrm{p}=0.009$, and $\mathrm{p}=0.048$, respectively) scores of patients with weight loss at the time of diagnosis were lower than those without weight loss. Fatigue $(p=0.010)$, dyspnea $(\mathrm{p}=0.032)$, and loss of appetite $(\mathrm{p}=0.013)$ scores of patients who had weight loss at the time of diagnosis were higher. However, no correlation was determined between HAD, nutritional condition questionnaires, and weight loss. On a subscale of EORTCQLQ-C30 questionnaire, physical function scores were lower in patients with lower albumin levels $(\mathrm{p}=0.006)$.

Patients with low ghrelin levels had the median of OS was 68 weeks, and it was 26 weeks in the patients with high ghrelin levels; however, the difference was not statistically significant (Figure 1). Among patients with high ghrelin levels, the median PFS was 22 weeks, whereas it could not be reached in patients with low ghrelin levels ( $p=0.023$ ) (Figure 2).
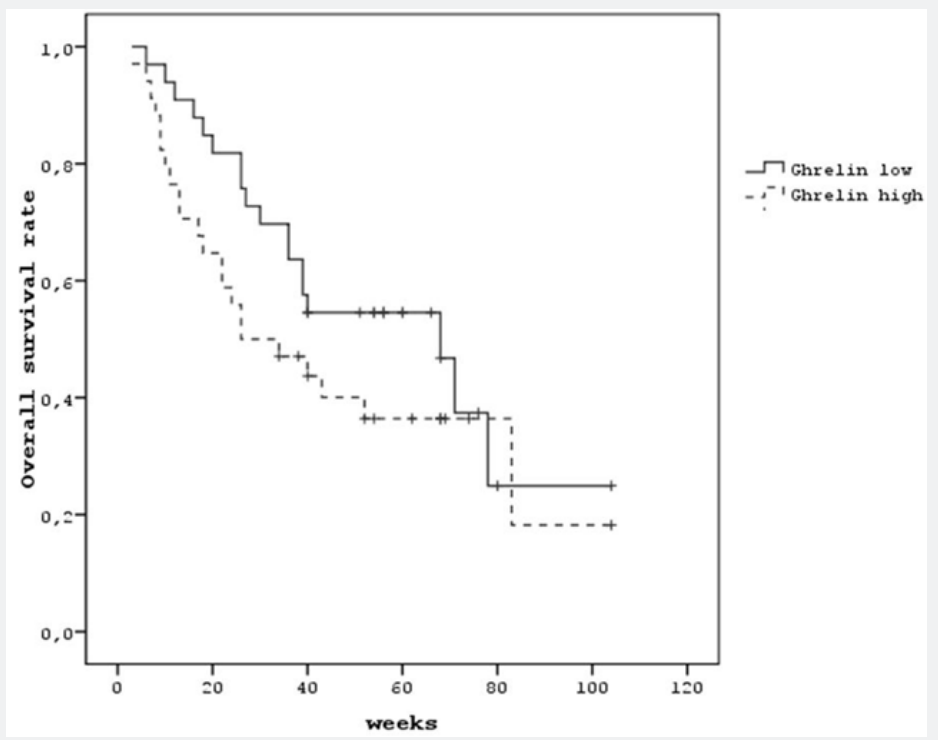

Figure 1: Kaplan - Meier overall survival curve according to ghrelin level 


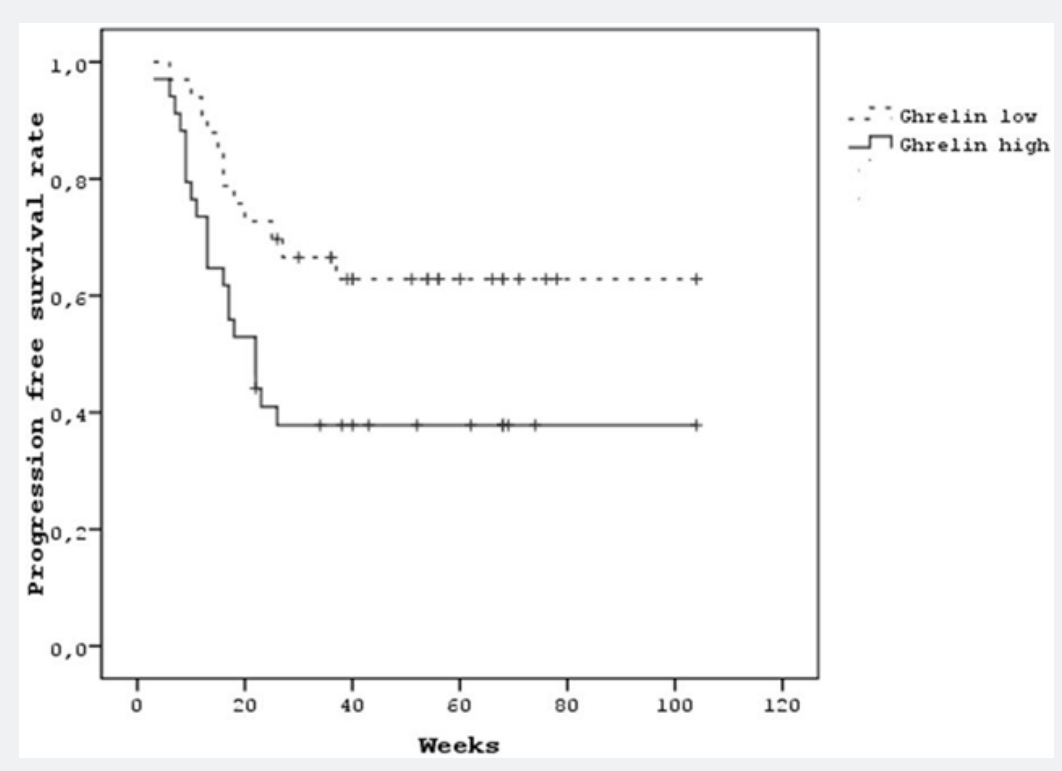

Figure 2: Kaplan - Meier progression-free survival curve according to ghrelin levels.

\section{Discussion}

Ghrelin is an orexigenic hormone, and it antagonizes leptin which decreases food intake [12]. Serum leptin levels were found significantly lower in lung cancer patients than healthy controls [13]. It is believed that ghrelin administration antagonizes effect of cytokines which act on appetite and weight loss [14]. Ghrelin levels are positively correlated with cachexia conditions like anorexia nervosa [15], chronic obstructive pulmonary disease [16] and end stage renal disease [17]. Ghrelin levels have been found lower in weight gain and obesity [15]. It was suggested that role of ghrelin in inflammatory process of cancer was cytokine inhibition, and it had also ant proliferative effects[18]. It was thought that ghrelin levels were increased through compensation caused by its anti-inflammatory effects.

In our study, ghrelin levels were found higher in patients who had weight loss at the time of diagnosis. It might be considered that increased ghrelin levels in cachectic patients were due to compensation of the catabolic process [19]. This hypothesis was supported by another study performed on patients with lung cancer (20). Basal ghrelin levels were determined significantly higher in cache tic patients, and it was observed that ghrelin levels were significantly increased in patients whose food intake was decreased on days 8 and 21 after chemotherapy [20]. These results indicated that anorexia might affect ghrelin levels in patients with lung cancer. In the same study, there was a correlation between PS and ghrelin, and ghrelin levels were measured significantly high in patients with poor PS [20]. In our study, only basal ghrelin levels were measured, but ghrelin levels after chemotherapy were not measured. Also, no correlation was found between PS and ghrelin levels.

It was thought that ghrelin might be increased to compensate anorexia, and short-term appetite loss, fasting, and re-starting food intake might affect ghrelin levels. Although ghrelin level is high in anorexic patients, and high ghrelin levels are expected to increase appetite, it is observed that these patients have loss of appetite. The possible cause of this loss of appetite is that, similar to insulin resistance mechanism, although ghrelin concentration is high in the blood, there may be a loss of ghrelin receptor affinity. Karapanagiotou [21] found that ghrelin levels were higher in the advanced NSCLC patient group. Studies performed on patients with lung cancer, ghrelin levels were higher in-patient groups than control subjects, however there was no statistical significance [20,21]. Basal ghrelin levels of patients with and without weight loss before chemotherapy were measured in 101 patients with advanced lung cancer and 60 healthy controls by Karapanagiotou [21].

Weight loss was observed in 75 patients, whereas there was no weight loss in 26 patients. Ghrelin levels were determined significantly higher in patients with weight loss at the time of diagnosis. In the same study, no correlation was determined between ghrelin levels and age, cancer stage, histological type, $\mathrm{PS}, \mathrm{PFS}$, and OS rates. It was underlined that OS rates were lower in patients with low BMI and poor performance despite an insignificant difference. In our study, ghrelin levels increased 2.8fold in patients with progression. No correlation was determined with OS.In a study performed on 14 breast cancer cases and 26 colon cancer cases, and 20 healthy controls, patients were divided into two groups as cache tic and non-cache tic. Ghrelin levels were found significantly higher in cache tic patients. Ghrelin levels in cache tic female patients were significantly higher than the levels in male patients [22]. In our study, there was no correlation between sex and ghrelin levels, but low number of female patients $(n=5)$ might be an effective factor in this issue. Jeon [23] compared sixteen cache tic patients with advanced gastrointestinal cancer ( 2 with esophagus, 9 with gastric, and 5 
with colorectal cancer), and ten healthy controls.Ghrelin levels were found significantly higher in cachectic patients, whereas no correlation was determined with BMI. The main tissue for ghrelin secretion is stomach, and it has been shown that ghrelin levels decreased after gastrectomy. In that study, 7 patients had total gastrectomy, but no significant difference was found in ghrelin levels in patients with and without gastrectomy [23] This condition was explained as ghrelin secretion from other tissues ( $\mathrm{T}$ cells, spleen, thymus, and intestines) could increase after gastrectomy by the compensatory secretion.

In a study performed in cache tic gastric, pancreatic and colorectal cancer patients, ghrelin levels decreased significantly[24]. This suggests our minds that there might be other special effects on ghrelin production in patients with gastrointestinal cancers. Therefore, it was reported that patients with gastrointestinal cancers might be the most suitable group for exogenous ghrelin administration. In a phase II, placebocontrolled, randomized study, ghrelin was administered to cache tic and non-cache tic tumor implanted rats, and 30\% elevation was reported in appetite and food intake [25]. Again, in a doubleblind, randomized, placebo-controlled study carried out on cache tic rats with cancer, favorable results of exogenous ghrelin administration were reported [26].

The present study and the other studies suggest that ghrelin has a compensatory role in pathogenesis of cancer cachexia, and it shows its effects through mediators affecting a systemic inflammation rather than mediators affecting fat metabolism. The small sample size and lack of ghrelin measurements after chemotherapy are limitations of this study. This study demonstrated that ghrelin levels were found to be higher in patients with weight loss at the time of diagnosis. Serum ghrelin levels are important in cancer and cancer cachexia; however, the utilization of ghrelin as a diagnostic or prognostic tool is not possible yet and further largescale studies are required to confirm our findings.

\section{References}

1. Deans C, Wigmore SJ (2005) Systemic inflamation, cachexia and prognosis in patients with cancer. Curr Opin Clin Nutr Metab Care 8: 265-269.

2. Vaitkus JA, Celi FS (2017) The role of adipose tissue in cancerassociated cachexia. Exp Biol Med (Maywood) 242(5): 473-481.

3. Ross PJ, Ashley S, Norton A (2004) Do patients with weight loss have a worse outcome when undergoing chemotherapy for lung cancers? Br J Cancer 90: 1905-1911.

4. Aydin S (2007) Ghrelin and clinical aspects. Turkish Biochemistry 32 76-89.

5. Nakazato M, Murakami N, Date Y (2001) A role for ghrelin in the central regulation of feeding. Nature 409: 194-198.

6. Ravasco P, Grillo IM, Camilo M (2006) Cancer Wasting and Quality of Life React to Earliy Individualized Nutritional Counselling! Clin Nutr 26(1): 7-15
7. Guzelant A, Goksel T, Ozkok S, Tasbakan S, Aysan T, et al. (2004) The European Organization for Research And Treatment of Cancer Qlq-C30: An Examination İnto The Cultural Validity and Reliability of the Turkish Version of the Eortc Qlq-C30. Eur J Cancer Care13: 135144 .

8. Fayers PM (2001) Interpreting quality of life data: population-based reference data for the EORTC QLQ-C30. Eur J Cancer Care37: 13311334.

9. Koçyiğit H, Aydemir Ö, Fișek G, Ölmez N (1999) Memiş A Kısa form -36 (KF-36) nın Türkçe versiyonunun güvenilirliği ve geçerliliği. İlaç ve Tedavi Dergisi 12: 102-106.

10. Carroll BT, Kathol RG, Noyes R, Wald TG, Clamon GH (1993) Screening for depression and anxiety in cancer patients using the Hospital Anxiety and Depression Scale. Gen Hosp Psychiatry 15: 69-74.

11. Aydemir Ö (1997) Turkish validation of HAD Scale. Turkish Psychiatry 8: 280-287.

12. Druce MR, Neary NM, Small CJ, Milton J, Monteiro M, et al. (2006) Subcutaneous administration of ghrelin stimulates energy intake in healthy lean human volunteers. Int J Obes 30: 293-296.

13. Demiray G, Değirmencioğlu S, Uğurlu E, Yaren A (2017) Effects of Serum Leptin and Resistin Levels on Cancer Cachexia in Patients With Advanced-Stage Non-Small Cell Lung Cancer Clin Med Insights Oncol 20: 11 .

14. Toshinai K, Mondal MS, Nakazato M, Date Y, Murakami N, et al. (2001) Upregulation of ghrelin expression in the stomach upon fasting, insülin-induced hypoglycemia and leptin administration. Biochem Biophys Res Commun 281: 1220-1225.

15. Otto B, Cuntz U, Fruehauf E, Wawarta R, Folwaczny C, et al. (2001) Weight gain decreases elevated plasma ghrelin concentrations of patients with anorexia nervosa. Eur J Endocrinol 145: 669-673.

16. Ying BW, Song XB, Fan H, Wang LL, Li YS, et al. (2008) Plasma ghrelin levels and weight loss in Chinese Uygur patients with chronic obstructive pulmonary disease. J Int Med Res 36(6): 1371-1377.

17. Aygen B, Dogukan A, Dursun FE, Aydin S, Kilic N, et al. (2009) Ghrelin and obestatin levels in end-stage renal disease. J Int Med Res 37(3): 757-765.

18. Dixit VD, Schaffer EM, Pyle RS, Collins GD, Sakthivel SK, et al. (2004) Ghrelin inhibits leptin- and activation-induced proinflammatory cytokine expression by human monocytes and T cells. J Clin Invest 114: 57-66.

19. Tolle V, Kadem M, Bluet-Pajot MT, Frere D, Foulon C, et al. (2003) Balance in ghrelin and leptin plasma levels in anorexia nervosa patients and constitutionally thin women. J Clin Endocrinol Metab 88: 109-116.

20. Shimizu Y, Noritoshi N, Takeshi I (2003) Increased plasma ghrelin level in lung cancer caxhexia. Clin Cancer Res 9: 774-778.

21. Karapanagiotou EM, Tsochatzis EA, Dilana KD, Tourkantonis I, Gratsias I, et al. (2008) The significance of leptin, adiponectin, and resistin serum levels in non-small cell lung cancer (NSCLC). Lung Cancer 61: 391-397.

22. Wolf I, Sadetzki S, Kanety H, Kundel Y, Pariente C, et al. (2006) Adiponectin, ghrelin, and leptin in cancer cachexia in breast and colon cancer patients. Cancer 106: 966-973.

23. Jeon TY, Lee S, Kim HH (2004) Changes in plasma ghrelin concentration immediately after gastrectomy in patients with early gastric cancer. J Clin Endocrinol Metab 89: 5392-5396.

24. Kemik O, Kemik AS, Begenik H, Erdur FM, Emre H, et al. (2012) The relationship among acute-phase responce proteins, cytokines, and 
hormones in various gastrointestinal cancer types patients with cachectic. Hum Exp Toxicol 31(2): 117-125.

25. De Boer MD, Zhu XX, Levasseur P, Meguid MM, Suzuki S, et al. (2007)
Ghrelin treatment causes increased food intake and retention of lean body mass in a rat model of cancer cachexia. Endocrinology 148: 3004-3012.

\section{Your next submission with Juniper Publishers will reach you the below assets}

- Quality Editorial service

- Swift Peer Review

- Reprints availability

- E-prints Service

- Manuscript Podcast for convenient understanding

- Global attainment for your research

- Manuscript accessibility in different formats

(Pdf, E-pub, Full Text, Audio)

- Unceasing customer service

Track the below URL for one-step submission https://juniperpublishers.com/online-submission.php 